\title{
Stereoselection at the Steady State in Radical Cyclizations of Acyclic Systems Containing One Radical Acceptor and Two Precursors in 1,5- Relationship under pseudo-First Order Conditions
}

\author{
Robert Andrukiewicz, Piotr Cmoch, Anna Gaweł and Krzysztof Staliński* \\ Institute of Organic Chemistry, Polish Academy of Sciences, Kasprzaka 44/52, 01-224 Warsaw, Poland
}

Stalinsk@icho.edu.pl

Abstract: The first example of a successive kinetic resolution of acyclic diastereomeric radical intermediates in 1,5-relationship under pseudo-first order conditions is reported. A mechanistic model involves non-selective generation of the radical intermediates followed by different partitioning of these between two different chemical pathways. The "2,5-cis" selectivity in the radical cyclization step arises from transition geometries with the substituents aligned in pseudoequatorial positions.

\section{Introduction}

The substituted tetrahydrofurans are of interest as building blocks in organic synthesis, chiral auxiliaries, and the structural units of many natural products. ${ }^{1,2}$ The stereoselective approach to this class of compounds is still problematic because of flexible transition states leading to the tetrahydrofuran system. ${ }^{3}$ Among the different strategies available free carbon radical cyclizations are of particular interest as an alternative to ionic ones. ${ }^{4}$ Especially $\beta$ alkoxyacrylates are excellent precursors for stereoselective preparation of $c i s-2,5$-substituted 
tetrahydrofurans via radical cyclizations. ${ }^{5}$ Another radical approach to tetrahydrofurans relies on the addition of electrophilic alkoxy radicals to multiple bonds. ${ }^{6}$

Recently, Curran has proposed a new type of stereoselective process founded on the transiency of radicals and called it "Stereoselection at the Steady State". 7 The most important difference between traditional multistep stereoselective processes and the proposed one seems to be selective partitioning of stereomeric intermediates at the steady state between two different chemical (not stereochemical) pathways to the same stereomeric product. ${ }^{8}$ Most of the existing examples of stereoselection at the steady state are diastereoselective and involve bi- and tricyclic systems. ${ }^{8,9}$ Due to lack of rigidity, acyclic systems seem to be more difficult in predicting a stereochemical outcome of the radical cyclizations. However, in most cases the major product(s) can be successfully predicted using the Beckwith-Houk model. ${ }^{10}$ So far only one acyclic system containing radical precursors in 1,3-relationship has been subjected to the stereoselection at the steady state (Scheme 1$).{ }^{11}$

\section{Scheme 1. The acyclic model containing precursors in 1,3-relationship}

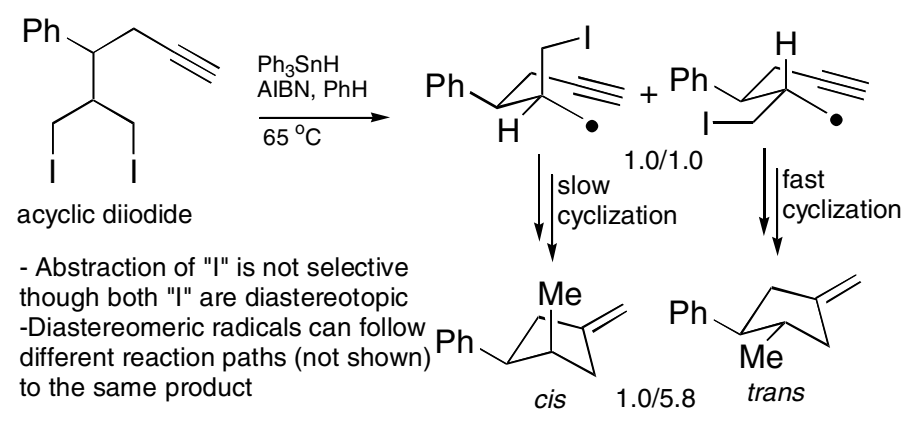

There are relatively few examples of desymmetrizations of pseudo $\mathrm{C}_{2}$-symmetric acyclic systems. ${ }^{12}$ All of them are outside radicals. Desymmetrization in such systems requires diastereotopic group selection. However, in the light of the stereoselection at the steady state group selection processes (obviously involved) do not directly control the level of 
stereoselection as they do in all known processes. The stereocontrol rather results from a complex interplay of reaction paths that diverge and reconverge at various points.

The present study was initiated by our interest in discovering examples of radicalbased processes of acyclic pseudo $\mathrm{C}_{2}$-symmetric precursors at the steady state leading to substituted tetrahydrofurans. The possibility of manipulation of stereocontrol by reaction topography prompted us to investigate whether radical cyclizations of acyclic vinyl ethers having two radical precursors in 1,5-relationship will meet the requirements of the stereoselective process. Herein, we wish to describe results of our efforts along these lines.

\section{Results and Discussion}

Diiodides 1 and $\mathbf{2}$ were designed as models representing pseudo $\mathrm{C}_{2}$-symmetric family of compounds having two radical precursors in 1,5-relationship and one radical acceptor. We assumed that transition states of the radical pair of monoiodides obtained after non-selective abstraction of first iodine atom from any of the dioiodides would adopt the chairlike geometry (Scheme 2). The chairlike transition state should favor products derived from intermediates having the substituents in pseudoequatorial positions. On the other hand substituents, which

are aligned pseudoaxially, should slow down the cyclizations. In both the radicals derived from 1 or 2 the methyl group adopts either the pseudoaxial or pseudoequatorial position. Therefore one of them was expected to close faster than the other one. We expected that at suitable trapping agent concentrations, the process would converge on the formation of one major product.

\section{Scheme 2. Models having two radical precursors in 1,5 relationship}




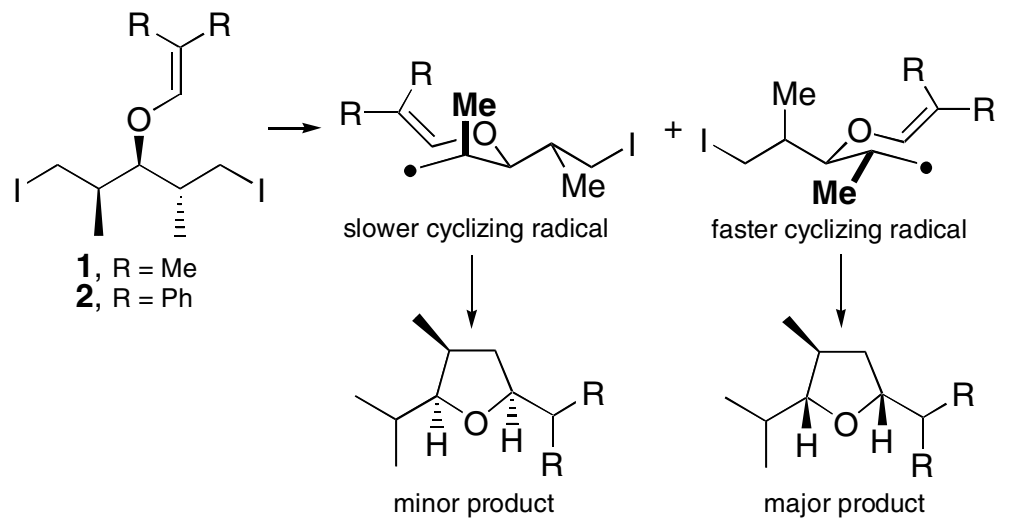

Both model compounds were obtained in a multistep synthesis starting from commercially available (S)-(+)-3-hydroxy-2-methylpropionate (Scheme 3). Compound 3 was prepared in four synthetic steps via chiral crotylboronates chemistry. ${ }^{13}$ The alcohol thus obtained was converted into acetonide 4 via TBS-deprotection and acetal protection with 2,2dimethoxypropane. Ozonolysis of $\mathbf{4}$, a reductive workup with $\mathrm{Me}_{2} \mathrm{~S}$ and treatment of the resulting aldehyde with sodium borohydride gave the corresponding alcohol $\mathbf{5}$ in $67 \%$ yield. Compound 5 was then either reacted with iodine to give iodide $\mathbf{6}$ or benzylated. Both the acetonides were then hydrolyzed to the corresponding diols, which after conversion to the primary iodides were treated with an excess of either diphenylacetaldehyde dimethylacetal or 1,1-dimethoxy-2-methylpropane in boiling benzene in the presence of an acid catalyst to give the radical precursors $\mathbf{1}, 2$ and 9.

Scheme 3. Synthesis of the radical precursors 1,2 and 9 


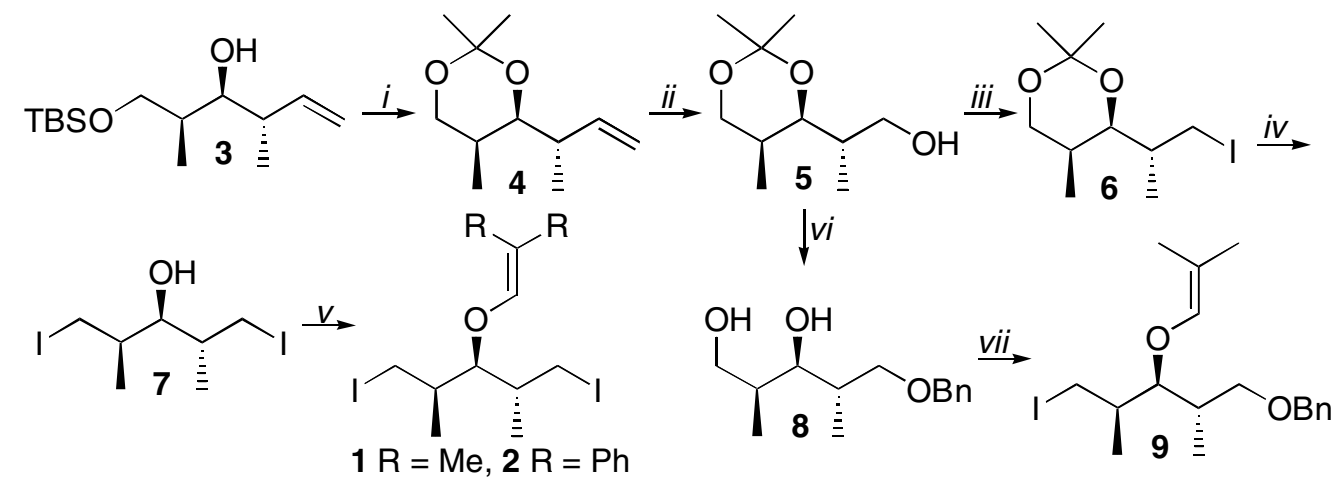

i) TBAF, THF, rt, $3 \mathrm{~h} 100 \%$; 2,2-dimethoxypropane, DMF, p-TSOH, rt, $24 \mathrm{~h}, 90 \%$; ii) $\mathrm{O}_{3}, \mathrm{MeOH} / \mathrm{CH}_{2} \mathrm{Cl}_{2},-78{ }^{\circ} \mathrm{C}$, $1.5 \mathrm{~h}, \mathrm{NaBH}_{4}, \mathrm{rt}, 16 \mathrm{~h}, 67 \%$; iii) I $\mathrm{I}_{2} \mathrm{Im}, \mathrm{Ph}_{3} \mathrm{P}, \mathrm{THF}, 3 \mathrm{~h}, 0{ }^{\circ} \mathrm{C}, 82 \%$; iv) $p-\mathrm{TSOH}, \mathrm{MeOH}, 24 \mathrm{~h}, \mathrm{rt}, 92 \% ; \mathrm{I}_{2}, \mathrm{Im}_{2} \mathrm{Ph}_{3} \mathrm{P}$, THF,3h, $0{ }^{\circ} \mathrm{C}, 82 \%$; v) 1,1-dimethoxy-2-methylpropane, PPTS, $\mathrm{PhH}$, reflux, $18 \mathrm{~h}, 78 \%$ or diphenylacetaldehyde dimethylacetal, $p$-TSOH, reflux, $24 \mathrm{~h}, 70 \%$; vi) $\mathrm{NaH}, \mathrm{BnBr}$, DMF, $0{ }^{\circ} \mathrm{C}, 24 \mathrm{~h}, 86 \%$; $p$-TSOH, $\mathrm{MeOH}, 24 \mathrm{~h}, \mathrm{rt}, 96 \%$; vii) $p$-TsCl, Py, $\mathrm{CH}_{2} \mathrm{Cl}_{2}, 0{ }^{\circ} \mathrm{C}, 24 \mathrm{~h}, 81 \%$; Nal, acetone, $65{ }^{\circ} \mathrm{C}, 24 \mathrm{~h}, 69 \%$; 1,1-dimethoxy-2-methylpropane, PPTS, $\mathrm{PhH}$, reflux, $18 \mathrm{~h}, 55 \%$.

Compound 9 was prepared in order to measure the rate constant of the slower cyclization. Radical cyclizations of $\mathbf{9}$ with tris(trimethylsilyl)silane (TTMSH) in the presence of $\mathrm{Et}_{3} \mathrm{~B} / \mathrm{O}_{2}$ at $\sim 20{ }^{\circ} \mathrm{C}$ gave four different products (Eq 1). ${ }^{14}$ The calculated rate constant was estimated as $1 \times 10^{5} \mathrm{~s}^{-1} \mathrm{M}^{-1}$. The value is in agreement with the rate constant of the rearrangement of 6,6-dimethyl-5-hexenyl radical to the isopropylcyclopentyl radical $\left(5 \times 10^{5} \mathrm{~s}^{-}\right.$ $\left.{ }^{1} \mathrm{M}^{-1}\right) .{ }^{15}$

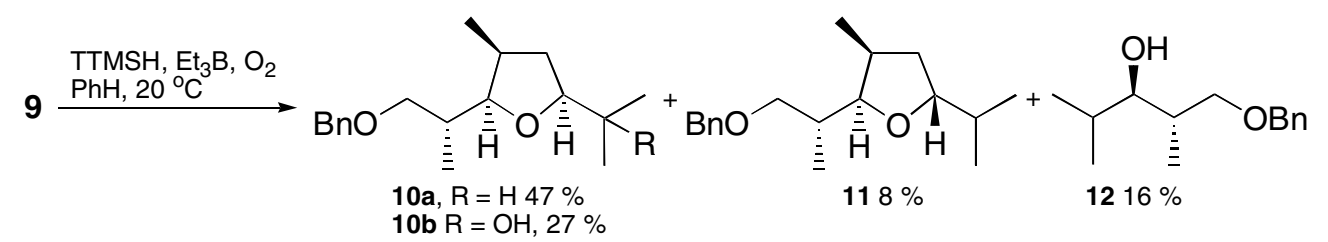

We next studied radical cyclizations of diiodide $\mathbf{1}$. A preparative cyclization of $\mathbf{1}$ was conducted under standard conditions at $0.05 \mathrm{M}$ TTMSH concentration (2.2 equiv.) in benzene at $\mathrm{rt}$. GC/MS analysis of the reaction mixture revealed formation of two major products, presumably the isomeric tetrahydrofurans as concluded from the MS spectra. Due to technical 
difficulties we had to abandon the radical cyclizations of $\mathbf{1}$ and move to $2 .{ }^{16}$ A preparative cyclization of 2 was conducted under the same standard conditions. The reaction provided two major products in a ratio of $\sim 1: 1$ in $90 \%$ yield and benzophenone $(7 \%)$. The products were separated by preparative HPLC, and individual pure samples of each were obtained (Eq 2).

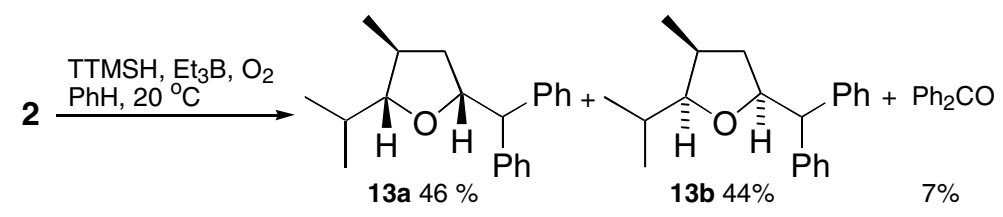

The structures of the cyclic products were derived from the $(\mathrm{H}, \mathrm{H})(\mathrm{C}, \mathrm{H})$ correlation experiments, and the NOE differential measurements. ${ }^{17}$ In order to properly describe the structures of the products of the radical cyclizations of $\mathbf{9}$ and $\mathbf{2}$ with TTMSH we decided to assign the ${ }^{1} \mathrm{H}$ NMR signals in spectra of compounds 10a, 11 and 13a,b. For this purpose two different NMR techniques, including ${ }^{1} \mathrm{H}^{-13} \mathrm{C}$ gradient selected HSQC and HMBC methods were used. Next we employed the results of NOE differential experiments. The results of the ${ }^{1} \mathrm{H}$ and ${ }^{13} \mathrm{C}$ NMR signal assignments for compounds 10a, 11, 13a,b are collected in supporting materials but the chosen NOE results are presented in Figure 1 and 2. At first we decided to determine the structure of the main product obtained after radical cyclization of 9 with TTMSH. In $\mathrm{C}_{6} \mathrm{D}_{6}, \mathrm{CDCl}_{3}$, acetonitrile- $d_{3}$, acetone- $d_{6}$ and methanol- $d_{4}$ signals of the $\mathrm{H} 2$, $\mathrm{H} 5$ protons as well as $\mathrm{H} 3$ and one of the $\mathrm{H} 4$ protons of $\mathbf{1 0 a}$ are very close to each other thus observation of the NOEs is rather complicated. However, basing on the results of the $\mathrm{H} 2-\mathrm{H} 3$, H4-H5, H4-H2 NOEs for 10a (Fig. 1) the stereochemistry of this compound could be determined with a relatively good probability. Additionally, in the NOESY experiment taken from 10a we found that dipolar interactions exist between the $\mathrm{H} 2$ and $\mathrm{H} 5$ protons. Based on 
the NOE and NOESY experiments we concluded that the H2, H3 and H5 protons share cis relationship.
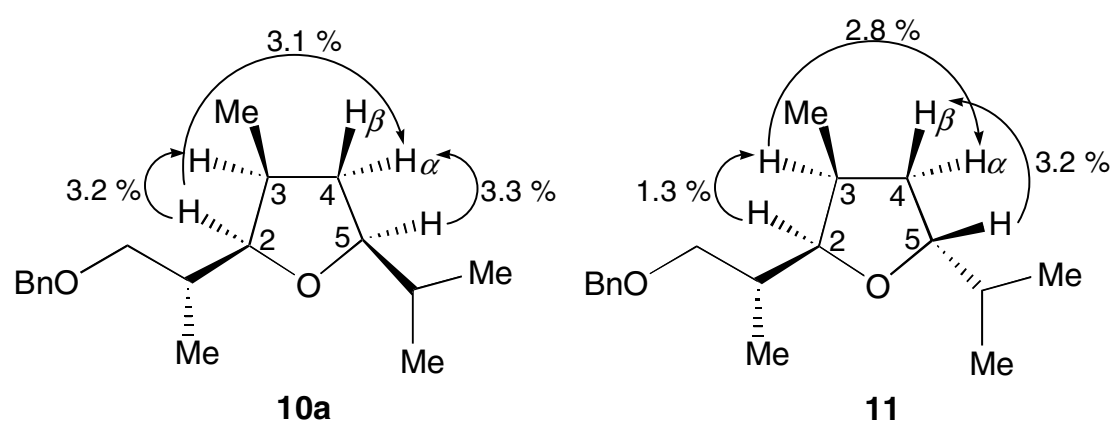

Figure 1. The ${ }^{1} \mathrm{H}$ NMR NOE results of compounds 10a and $\mathbf{1 1 .}$

Contrary to the structure of $\mathbf{1 0 a}$, where the $\mathrm{H} 2, \mathrm{H} 3$ and $\mathrm{H} 5$ protons are in cis position to each other the analysis of NOE differential measurements for $\mathbf{1 1}$ suggests that protons $\mathrm{H} 2$ and H5 are in trans relationship. This suggestion is supported by the NOE effects observed after irradiation of all well separated ${ }^{1} \mathrm{H}$ NMR signals at 3.55 (H5), 3.39 (H2), 2.00 (H3), 1.71 $(\mathrm{H} 4 \alpha)$ and $1.47(\mathrm{H} 4 \beta)$. A careful analysis of the NOE effects for 11, where weak but measurable NOE effects (Fig. 1) for pairs $\mathrm{H} 3-\mathrm{H} 4 \alpha, \mathrm{H} 2-\mathrm{H} 3, \mathrm{H} 4 \beta-\mathrm{H} 5$ were observed, indicates that this time protons $\mathrm{H} 2, \mathrm{H} 3$ and $\mathrm{H} 4 \alpha$ share cis relationship.

The stereochemistry of isomeric tetrahydrofurans 13a,b was also determined on the basis of the ${ }^{1} \mathrm{H}$ NMR NOE measurements. In the case of 13a,b almost all signals of the aliphatic protons, including $\mathrm{H} 2$ and $\mathrm{H} 5$, were well separated (in different solvents) thus the interpretation of the ${ }^{1} \mathrm{H}$ NMR NOE experiments was rather straightforward. The most significant NOEs observed for 13a and $\mathbf{1 3 b}$ are presented in Figure 2. At first we decided to determine the structure of the compound obtained with $44 \%$ yield (Eqn 2). Irradiation of the $\mathrm{H} 2$ signal $(\delta=4.46 \mathrm{ppm})$ leads to observation of NOE $(4.8 \%)$ at $\mathrm{H} 5(3.20 \mathrm{ppm})$, and two indistinguishable effects at $\mathrm{H} 3 \alpha(1.98 \mathrm{ppm})$ and $\mathrm{H} 4$ (1.96 ppm). When $\mathrm{H} 5$ was irradiated one 
measurable effect $(4.8 \%)$ was observed at $\mathrm{H} 2(\delta=4.46 \mathrm{ppm})$ and an additional enhancement at $\delta=\sim 1.97 \mathrm{ppm}(\mathrm{H} 3 \alpha$ and $\mathrm{H} 4)$ was also detected. Irradiation of the signal at $\delta=1.26 \mathrm{ppm}$ $(\mathrm{H} 3 \beta)$ caused another effect $(1.9 \%)$ at $0.74 \mathrm{ppm}$ (methyl group at $\mathrm{C} 4)$. Furthermore, two other enhancements were observed. Proton $(\mathrm{CH})$ of the iso-propyl group at $1.77 \mathrm{ppm}$ interacts with the methyl group at $\mathrm{C} 4$, and $\mathrm{H} 3 \beta$ interacts strongly with proton from the benzhydryl group at $\delta=4.07 \mathrm{ppm}$. The above-mentioned effects suggest that the $\mathrm{H} 2, \mathrm{H} 3 \alpha, \mathrm{H} 4$ and $\mathrm{H} 5$ protons are in cis position to each other and the structure of this compound is $\mathbf{1 3 b}$.

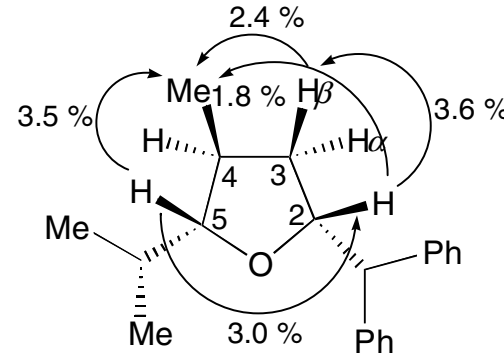

$13 a$

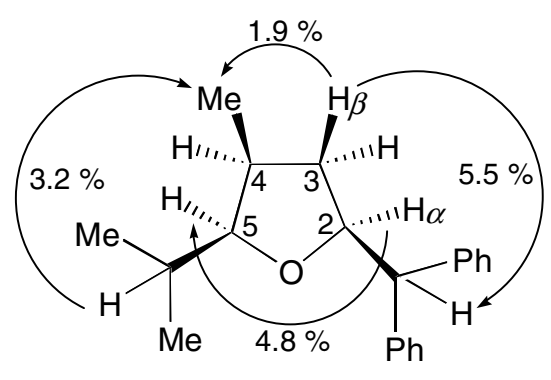

$13 b$

Figure 2. The ${ }^{1} \mathrm{H}$ NMR NOE results of compounds $\mathbf{1 3 a}, \mathbf{b}$.

In the case of $13 \mathbf{a}$ (46\% yield) a relatively strong effect (3.0\%) between the $\mathrm{H} 2$ and $\mathrm{H} 5$ protons was observed. Irradiation of the $\mathrm{H} 2$ proton at $4.61 \mathrm{ppm}$ provided an additional effect at $1.34 \mathrm{ppm}(3.6 \%, \mathrm{H} 3 \beta)$, whereas irradiation of the $\mathrm{H} 3 \beta$ proton gives an answer at $4.61 \mathrm{ppm}$ $(5.1 \%, \mathrm{H} 2)$. Medium effects were obtained for the methyl group (C4) at $0.86 \mathrm{ppm}$, when the H2 $(1.8 \%)$ and H5 (3.5\%) protons were respectively irradiated. Similarly to $\mathbf{1 3 b}$ two other effects were observed. Proton $(\mathrm{CH})$ of the iso-propyl group at $1.69 \mathrm{ppm}$ interacts only with the $\mathrm{H} 5$ proton, whereas proton from the benzhydryl group $(\delta=4.00 \mathrm{ppm})$ interacts strongly with that at $1.34 \mathrm{ppm}$. All the NOE enhancements obtained for 13a suggest that the $\mathrm{H} 2, \mathrm{H} 3 \beta$, H5 and protons of the methyl group (C4) share cis relationship. 
The two diastereomeric radicals shown in Scheme 2 were expected to cyclize at different rates. The assumption was made on the basis of analysis of the corresponding Beckwith-Houk models. For such a purpose the rate constants of the competing process (reduction of the first and second pair of the radicals) must be between the rate constants of both cyclizations. This was clearly not the case when typical hydrides were used. None of the tested hydrides (TTMSH, $n-\mathrm{Bu}_{3} \mathrm{SnH}, \mathrm{Ph}_{3} \mathrm{SnH}$ ) was fast enough to compete with the cyclizations. Even experiments with 5 equivalents of $\mathrm{Ph}_{3} \mathrm{SnH}$ at lower temperatures did not alter the ratio of the products. The rate constant of the rearrangement of the 6,6-diphenyl-5hexenyl radical to the cyclopentyldiphenylmethyl radical has been reported as $4 \times 10^{7} \mathrm{~s}^{-1} \mathrm{M}^{-1}$ at $20{ }^{\circ} \mathrm{C} .{ }^{18}$ We roughly estimated that the rate constant of diiodide 2 could be in the range of $5 \times 10^{7}-10^{9} \mathrm{~s}^{-1} \mathrm{M}^{-1}{ }^{19}$

Recently, Newcomb introduced the use of hydrogen atom abstraction from $\mathrm{PhSeH} .{ }^{20}$ The rate constant for trapping of radicals at $25{ }^{\circ} \mathrm{C}$ was determined as $2.1 \times 10^{9} \mathrm{M}^{-1} \mathrm{~s}^{-1}$. However, $\mathrm{PhSeH}$ is a very unpleasant substance. It is noxious and must be handled with care. ${ }^{21}$ Fortunately, it can be introduced in the form of $\mathrm{PhSeSePh}$ and generated by the addition of $n-\mathrm{Bu}_{3} \mathrm{SnH}$ as reported by Crich (Eq 3). ${ }^{22}$ Taking into account that $\mathrm{PhSeH}$ reacts with primary alkyl radicals $\sim 20$ times faster than $\mathrm{PhSH}^{23}$ and $\sim 1000$ times faster than $n$ $\mathrm{Bu}_{3} \mathrm{SnH}$ and its recycling is immediate; $\mathrm{PhSeH}$ seems to be the fastest pseudo-first order radical trapping agent. The most striking advantage in comparison with other trapping agents is that only a small or even catalytic amount of $\mathrm{PhSeH}$ is necessary to establish the conditions for pseudo-first order kinetics. Thus, we decided to take advantage of a polarity-matched reaction in radical cyclizations of diiodide $\mathbf{2}$. 


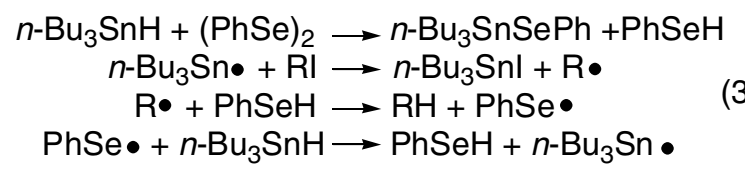

The appropriate amount of $\mathrm{PhSeH}$ was estimated performing three radical experiments with 50, 200 and $500 \mathrm{~mol} \%$ of $\mathrm{PhSeH}$ generated in situ from $\mathrm{PhSeSePh}$ and $n$-Bu $3 \mathrm{SnH} .500 \mathrm{~mol} \%$ excess of $\mathrm{PhSeH}$ appeared to give the highest $\mathbf{1 3 a} / \mathbf{1 3 b}$ ratio and it was used for further radical cyclizations of diiodide 2 at different $\mathrm{PhSeH}$ concentrations (Table 1).

Table 1. Radical cyclizations of 2 with $n-\mathrm{Bu}_{3} \mathrm{SnH} / \mathrm{PhSeH}$ at $70{ }^{\circ} \mathrm{C}$

\begin{tabular}{|c|c|c|c|c|c|c|}
\hline entry & {$[\mathrm{PhSeH}]$} & 13a/13b & $13 \mathbf{a}(\%)$ & 13b $(\%)$ & $13 \mathbf{a}+13 \mathbf{b}(\%)$ & $\mathbf{P h}_{2} \mathbf{C O}(\%)$ \\
\hline 1 & 0.05 & 1.06 & 48 & 45 & 93 & 2 \\
\hline 2 & 0.10 & 1.84 & 59 & 32 & 91 & 4 \\
\hline 3 & 0.13 & 2.33 & 63 & 27 & 90 & 6 \\
\hline \multirow[t]{3}{*}{4} & 0.20 & 2.95 & 69 & 23 & 92 & 3 \\
\hline & & $1.32^{a}$ & $53^{a}$ & $40^{a}$ & $93^{a}$ & 3 \\
\hline & & $1.84^{b}$ & $59^{b}$ & $32^{b}$ & $91^{b}$ & 5 \\
\hline 5 & 0.29 & 4.33 & 65 & 15 & 80 & 14 \\
\hline 6 & 0.51 & 5.90 & 59 & 10 & 69 & 24 \\
\hline 7 & 1.00 & 7.66 & 46 & 6 & 52 & 41 \\
\hline
\end{tabular}

In each experiment a strictly degassed solution of $\mathrm{PhSeSePh}$ in benzene was treated with an equimolar amount of the hydride and mixed until the yellow color was discharged. Then the diiodide 2 was added and heated for $2 \mathrm{~h}$ during which time a solution of the hydride and AIBN in benzene were added dropwise. After the reaction was completed the solvent was 
removed and the reaction mixture passed through a pad of silica gel. The ratio of $\mathbf{1 3 a} \mathbf{a} \mathbf{1 3 b}$ was determined using GC/MS with 9-fluorenone as an internal standard. ${ }^{24}$ Each of the products was calibrated against the standard. The ratio of $\mathbf{1 3 a} / \mathbf{1 3 b}$ appeared to depend on the concentration of $\mathrm{PhSeH}$. Starting from relatively low $\mathrm{PhSeH}$ concentrations the process converged on the formation of 13a. However, in all the radical experiments the doubly reduced product 19 was not isolated. The absence of $\mathbf{1 9}$ is incompatible with the proposed kinetic scheme 4 . When an authentic sample of $\mathbf{1 9}^{25}$ was treated with the tin hydride and AIBN in benzene at $70{ }^{\circ} \mathrm{C}$ for $48 \mathrm{~h}$ benzophenone was formed $(84 \%)$. We have also observed some unidentified minor products. Thus, the consumption of $\mathbf{1 9}$ could be explained in terms of hydrostannylation of the double bond and further radical rearrangements leading mainly to benzophenone. Further investigations concerning the formation of benzophenone are in progress.

Scheme 4 summarizes all the possible reaction pathways, which can be envisioned during the radical cyclization at the steady state of diiodide 2 . The first pair of isomeric radicals 14a,b is formed in a non-selective way. ${ }^{26}$ Both the radicals can either cyclize in the 5exo fashion giving 15a,b or be reduced to monoiodides 16a,b. However, the cyclizations occur at different rates due to pseudoequatorial or pseudoaxial position of the methyl group in $\mathbf{1 4 a}, \mathbf{b}$. We propose that at suitable trapping agent concentrations the slower cyclizing $\mathbf{1 4 b}$ is mostly reduced to $\mathbf{1 6 b}$ while the faster cyclizing $14 \mathbf{a}$ closes to $\mathbf{1 5 a}$. Cyclic monoiodides $\mathbf{1 5 a}, \mathbf{b}$ are reduced via radicals $\mathbf{1 7} \mathbf{a}, \mathbf{b}$ to the tetrahydrofurans $\mathbf{1 3 a}, \mathbf{b}$. The process repeats again in the second stage, where the roles of the radicals $\mathbf{1 8 a}, \mathbf{b}$ are now reversed. Now radical 18a is preferably reduced to the doubly reduced 19 while $\mathbf{1 8 b}$ closes to $13 \mathbf{a}$. The difference in the rates of reduction and cyclization of the first $(\mathbf{1 4 a}, \mathbf{b})$ and the second $(\mathbf{1 8 a}, \mathbf{b})$ pair of radicals is crucial, as suggested by Curran for the overall outcome of the radical process at the steady state. Such a difference sets up a concentration gradient that allows the slower cyclizing 
radicals $\mathbf{1 4 b}$ and $\mathbf{1 8 a}$ to be mostly reduced while the faster cyclizing radicals $\mathbf{1 4 a}$ and $\mathbf{1 8 b}$ to cyclize to 13a. Taking into account that the former pair leads to $\mathbf{1 3 b}$ and the latter to $\mathbf{1 3 a}$ further increase of the $\mathrm{PhSeH}$ concentration results in the preferable formation of 13a. Therefore the yield of 13a can exceed the level of stereoselection in the lowest stereoselective step, i.e. non-selective formation of the first pair of radicals $(\mathbf{1 4 a}, \mathbf{b})$.

Scheme 4. The overall kinetic framework for stereoselection at the steady state in the radical cyclizations of diiodide 2

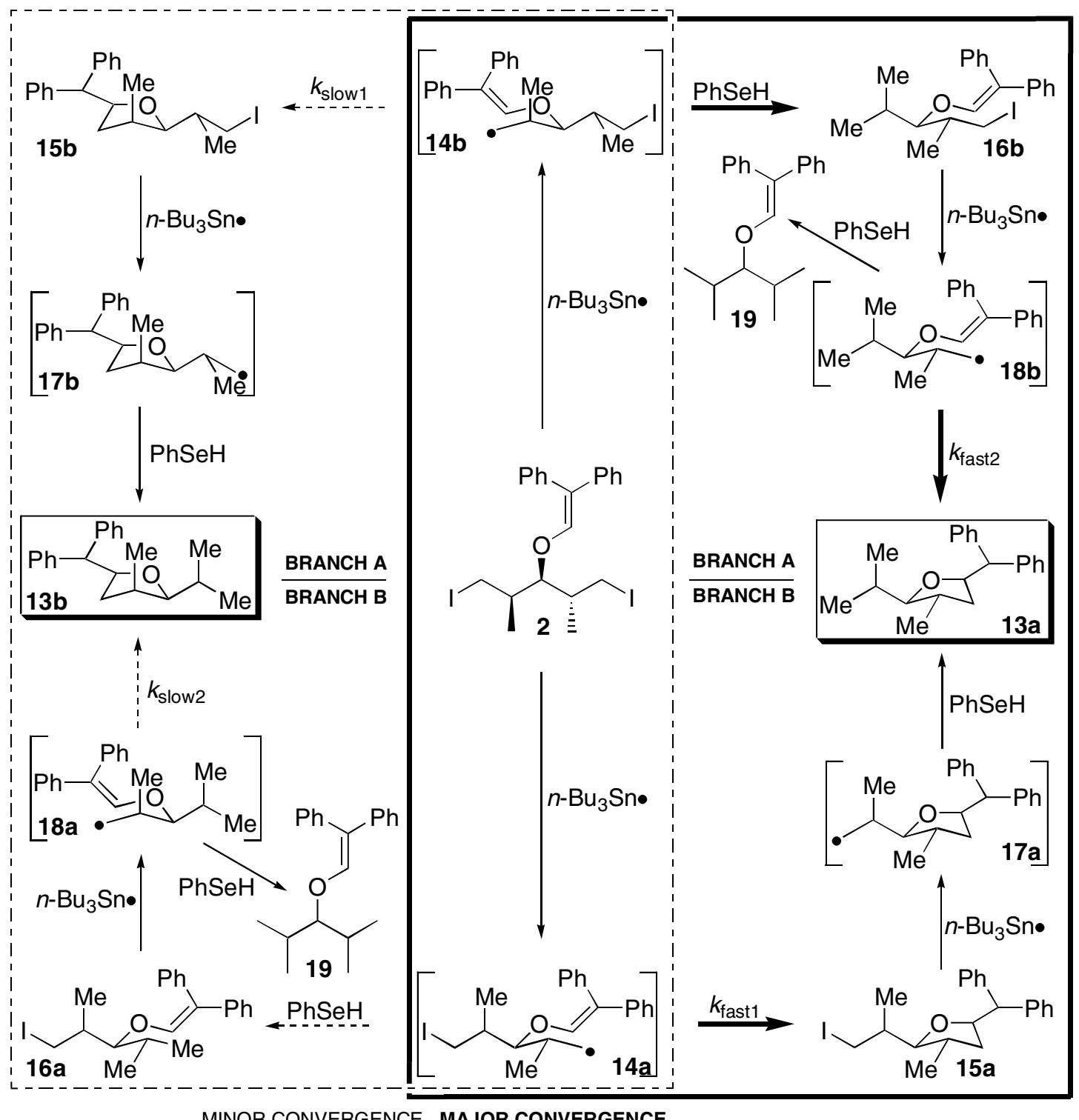


a Bold arrows represent faster reactions. Dashed arrows represent slower reactions. Standard arrows represent nonselective reactions.

\section{Conclusions}

The radical cyclizations of diiodide 2 provide another efficacious example of manipulation of stereocontrol by reaction topography. At suitable $\mathrm{PhSeH}$ concentration high 13a/13b ratios can be achieved. The yields of the major product are higher than the level of selectivity in the group-selective step. The results clearly support Curran's kinetic model. The 2,5-cis selectivity of the products arises from chairlike transition states with the pseudoequatorial substituents. This approach might be of further use wherever functionalized alkyl tetrahydrofurans are needed in organic chemistry. Further efforts towards diastereo- and enantioselective variants of stereoselection at the steady state will be reported in due course.

Acknowledgment: Financial support by the Institute of Organic Chemistry, Polish Academy of Sciences and the State Committee for Scientific Research (Grant No. 4 T09A 063 25) is gratefully acknowledged.

Supporting Information Available: The complete experimental details, copies of the ${ }^{1} \mathrm{H}$ and

${ }^{13} \mathrm{C}$ spectra for all new compounds. This material is available free of charge via the Internet at http://pubs.acs.org. 


\section{References}

${ }^{\ddagger}$ Dedicated to Prof. Dennis P. Curran for his fundamental contribution to the Stereoselection at the Steady State.

${ }^{1}$ Lord, M. D.; Negri, J. T.; Paquette, L. A. J. Org. Chem. 1995, 60, 191-195.

2 a) Shaw, D. E.; Fenton, G.; Knight, D. W. J. Chem. Soc., Chem. Commun. 1994, 2447-2448.

b) Paolucci, C.; Mazzini, C.; Fava, A. J. Org. Chem. 1995, 60, 169-175.

${ }^{3}$ Trost, B. M.; Li, C.-J. J. Am. Chem. Soc. 1994, 116, 10819-10822.

${ }^{4}$ Bartlett, P. A. Asymmetric Synthesis; Morrison, J. D.; Ed.; Academic Press: New York 1984, $3,411-453$.

${ }^{5}$ a) Lee, E.; Choi, S. J. Organic Letters 1999, 7, 1127-1128; b) Lee, E.; Song, H. Y.; Kim, H. J. J. Chem. Soc., Perkin Trans. 1 1999, 3395-3396; c) Lee, E.; Jeong, E. J.; Kang, E. J.; Sung, L. T.; Hong, S. K. J. Am. Chem. Soc. 2001, 123, 10131-10132.

${ }^{6}$ Hartung, J.; Gallou, F. J. Org. Chem. 1995, 60, 6706-6716.

${ }^{7}$ a) Curran, D. P.; DeMello, N. C. J. Am. Chem. Soc. 1998, 120, 329-341. b) Curran, D. P.; DeMello, N. C.; Junggebauer, J.; Lin, C.-H. J. Am. Chem. Soc. 1998, 120, 342-351.

${ }^{8}$ Kagan, H. Tetrahedron 2001, 47, 2449-2468.

${ }^{9}$ a) Curran, D. P.; Qi, H. Helvetica Chimica Acta 1996, 79, 21-30. b) Curran, D. P.; Qi, H.; DeMello, N. C.; Lin C.-H. J. Am. Chem. Soc. 1994, 116, 8430-8431. c) Villar, F.; Equey, O.; Renaud, P. Org. Lett. 2000, 2, 1061-1064.

${ }^{10}$ a) Spellmeyer, D. C.; Houk, K. N.; J. Org. Chem. 1987, 52, 959-974. c) Beckwith, A. L. J.; Lawrence, T.; Serelis, A. K. J. Chem. Soc., Chem. Commun. 1980, 482-483. c) Beckwith, A. L. J.; Easton, C. J.; Serelis, A. K. J. Chem. Soc., Chem. Commun. 1980, 484-485.

${ }^{11}$ Curran, D. P.; Staliński, K. J. Org. Chem. 2002, 67, 2982-2988. 
${ }^{12}$ Magnuson, S. R. Tetrahedron 1995, 51, 2167-2213 and references therein.

${ }^{13}$ a) Roush, W. R.; Ando, K.; Powers, D. B.; Palkowitz, A. D.; Halterman, R. L. J. Am. Chem. Soc. 1990, 112, 6339-6348. b) Roush, W. R.; Ando, K.; Palkowitz, A. D. J. Am. Chem. Soc. 1990, 112, 6348-6359.

${ }^{14}$ Compounds $\mathbf{1 0 a}, \mathbf{b}$ are formed via a chairlike transition state. Compound $\mathbf{1 1}$ is presumably formed via a boatlike transition state.

${ }^{15}$ Rate constants for 5-exo cyclizations of alkenyl radicals at $25{ }^{\circ} \mathrm{C}$ are in the range of $1-5 \times 10^{5}$ $\mathrm{s}^{-1} \mathrm{M}^{1}$, see: a) Lusztyk, J.; Maillard, B.; Deycard, S.; Lindsay, D. A.; Ingold, K. U. J. Org. Chem. 1987, 52, 3509-3514. b) Beckwith, A. L. J.; Easton, C. J.; Lawrence, T.; Serelis, A. K. Aust. J. Chem. 1983, 36, 545-556. c) Chatgilialoglu, C.; Ferreri, C.; Lucarni, M. J. Org. Chem. 1991, 56, 6399-6403.

${ }^{16}$ The products could not be separated by chromatography to give the individual pure isomers. Moreover, they appeared to be quite volatile and we were not able to purify them from impurities. The phenyl groups in $\mathbf{2}$ allowed us to separate the reaction mixture by means of HPLC (UV detection) and added molecular weight so that the products were not volatile.

${ }^{17}$ The ${ }^{1} \mathrm{H}$ NMR NOE enhancements in tetrahydrofurans are usually smaller than in other systems, see: Kadota, T.; Oguro, N.; Yamamoto, Y. Tetrahedron Letters 2001, 42, 36453648 .

${ }^{18}$ Newcomb, M.; Horner, J. H.; Filipowski, M. A.; Ha, C.; Park, S.-U. J. Am. Chem. Soc. 1995, 117, 3674-3684.

${ }^{19}$ One might hope that the relatively slow delivery of hydrogen to the first pair of radicals could be compensated by a huge excess of $\mathrm{Ph}_{3} \mathrm{SnH}$. But the analysis of small quantities of the products in the presence of a large excess of the hydride could be very difficult and give rather inconsistent results. Therefore, we then turned our attention to the use of much faster trapping agents. 
${ }^{20}$ Newcomb, M.; Varick, T. R.; Ha, Ch.; Manek, M. B.; Yue, X. J. Am. Chem. Soc. 1992, 114, 8158-8163.

${ }^{21}$ Paulmier, C. Selenium Reagents and Intermediates in Organic Synthesis; Pergamon Press: Oxford, 1986, 26.

${ }^{22}$ Crich, D.; Jiao, X.-Y.; Yao, Q.; Harwood, J. S. J. Org. Chem. 1996, 61, 2368-2373.

${ }^{23}$ Franz, J. A.; Bushaw, B. A.; Alnajjar, M. S. J. Am. Chem. Soc. 1989, 111, 268-275.

${ }^{24}$ Re-subjected 13a,b to the reaction conditions appeared to be stable and were recovered almost quantitatively (>96\%).

${ }^{25}$ For the comparison purpose 19 was prepared independently. Commercially available diisopropyl ketone was reduced with lithium aluminum hydride, and the resulting alcohol was reacted with excess of 1,1-dimethoxy-2,2-diphenylacetaldehyde acetal in the presence of $p$ toluenesulfonic acid.

${ }^{26}$ A reversible iodine transfer does not seem to play a role, see: a) Newcomb, M.; Sanchez, R. M.; Kaplan, J. J. Am. Chem. Soc. 1987, 109, 1195-1199. b) Newcomb, M.; Curran, D. P. Acc. Chem. Res. 1988, 21, 206-214. c) Drury, R. F.; Kaplan, L. J. Am. Chem. Soc. 1972, 94, 39823986. 
Table of Contents Graphic

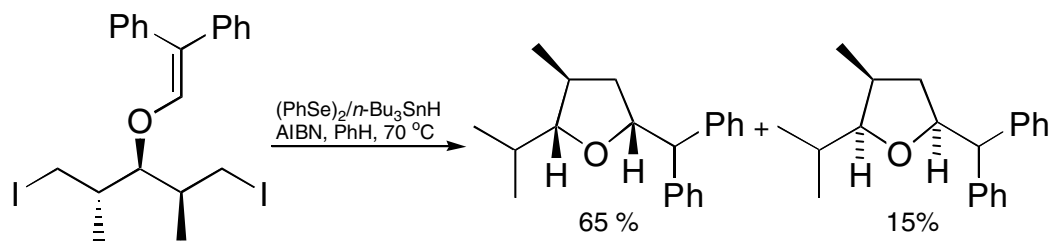

